\title{
Effect of 7-Nitroindazole, a Neuronal Nitric Oxide Synthase Inhibitor, on Behavioral and Physiological Parameters
}

\author{
C. BROŽÍČKOVÁ ${ }^{1}$, A. MIKULECKÁ ${ }^{1}$, J. OTÁHAL $^{1}$ \\ ${ }^{1}$ Department of Developmental Epileptology, Institute of Physiology, Academy of Sciences of the \\ Czech Republic, Prague, Czech Republic
}

Received March 20, 2014

Accepted April 16, 2014

On-line June 5, 2014

\begin{abstract}
Summary
The role of brain derived nitric oxide in the physiology and behavior remains disputable. One of the reasons of the controversies might be systemic side effects of nitric oxide synthase inhibitors. Therefore, under nNOS inhibition by 7nitroindazole (7-NI) we carried out recordings of blood gasses, blood pressure and spontaneous EEG in conscious adult rats. Locomotion and spontaneous behavior were assessed in an open field. In addition skilled walking and limb coordination were evaluated using a ladder rung walking test. The blood gas analysis revealed a significant increase in pCO2 $180 \mathrm{~min}$ and $240 \mathrm{~min}$ after the application of 7-NI. The power and entropy decreased simultaneously with a shift of the mean frequency of the spontaneous EEG toward slow oscillations after 7-NI treatment. The thresholds of evoked potentials underwent a significant drop and a trend towards a slight increase in the I-O curve slope was observed. 7-NI significantly suppressed open field behavior expressed as distance moved, exploratory rearing and grooming. As for the ladder rung walking test the 7-NI treated animals had more errors in foot placement indicating impairment in limb coordination. Therefore our findings suggest that 7-NI increased cortical excitability and altered some physiological and behavioral parameters.
\end{abstract}

\section{Key words}

7-nitroindazole • Open field test • Ladder rung walking test • Brain excitability $\bullet$ Blood gas analysis $\bullet$ Rat

\section{Corresponding author}

J. Otáhal, Institute of Physiology, Academy of Sciences of the Czech Republic, Vídeňská 1083, 14220 Prague 4, Czech Republic. Fax: +420-241062488. E-mail: jotahal@epilepsy.biomed.cas.cz

\section{Introduction}

Nitric oxide (NO) is a highly difusable gasseous signaling molecule with a short half-life which is involved in the regulation of many functions in the CNS under physiological and pathophysiological states (Brožíčková and Otáhal 2013, Kovacs et al. 2009). NO is synthesized by a family of enzymes nitric oxide synthases (NOS) present in several cell types of the organism. Neuronal nitric oxide synthase (nNOS) is mainly expressed in neurons of the brain, but has also been identified by immunohistochemistry in various peripheral organs (Forstermann et al. 1994). The omnipresent localization of nNOS demonstrates its implication in a wide range of physiological processes (Forstermann and Sessa 2012).

The main NO cellular signaling pathway in the brain is the activation of the guanylate cyclase (GC) cascade with the final step leading to a reduction of cytosolic calcium (Esplugues 2002). Other cellular action of NO independent of soluble guanylate cyclase (sGC) is the modulation of oxidative phosphorylation in the mitochondria by inhibition of complexes of respiratory chain (Brown 2001, Scatena et al. 2007). This suggests an important role in regulation of energy generation in the neurons. The action of NO is limited by its biologic half life which is up to 1 second in vivo and by a relative short distance that this molecule can pass. The NO reacts with other molecules forming highly reactive nitrogen and oxygen species which have the potential to interact with important cellular compartments and molecules leading to irreversible alterations. $\mathrm{NO}$ is considered to play an 
important role in regulation of regional cerebral blood flow (CBF) and its adjustment to fulfill metabolic demands of the surrounding brain tissue during activation. The hemodynamic response (neurovascular coupling) to brain activity is characterized by the vasodilatation of brain arterioles which is mediated mainly by NO and prostanoids with approximately same magnitude (Hoffmeyer et al. 2007). Recently, we have shown that systemic application of 7-NI, a specific inhibitor of nNOS (Engelhardt et al. 2006, Hoffmeyer et al. 2007), in urethane anesthetized rats significantly increased systemic blood pressure (BP), however, basal CBF remain unchanged (Brožíčková and Otáhal 2013). Moreover, the selective inhibition of nNOS was reported to diminish hemodynamic response to the brain stimulation (Brožíčková and Otáhal 2013, Hoffmeyer et al. 2007, Stefanovic et al. 2007). Besides vascular effects of NO in the brain further regulatory processes have been attributed to the nitric oxide since its first recognition as a signaling molecule in the central nervous system. NO is considered to take part in the regulation of synaptic transmission and plasticity (Bon and Garthwaite 2003, Garthwaite et al. 1988) or in inflammatory processes (Bal-Price and Brown 2001). NO thus indirectly influences various brain functions.

We have shown recently that NO of neuronal origin plays an important role in seizure generation during SE induced by kainic acid in mice in vivo. Our results suggest that NO may be responsible for some neurobiological changes associated with the development of chronic epilepsy (Beamer et al. 2012). In addition, inhibition of nNOS delayed the initiation of epileptic activity in low-Mg model of seizures in organotypic hippocampal slice cultures and acute slices from nNOS knockout mice (Kovacs et al. 2009). However, some in vivo studies on the role of $\mathrm{NO}$ in the pathophysiology of epilepsy have revealed contradictory results. The effects of nNOS inhibition varies from anticonvulsive to proconvulsive (Del-Bel et al. 1997, Itoh and Watanabe 2009) or from neuroprotective to toxic (Silverman 2009, Calabrese et al. 2007). The opposite actions of nNOS inhibition might not only be related to the model, dosage, specificity and application protocol but also to other systemic effects of the nNOS inhibitor in vivo. Furthermore, NO has been proposed to significantly modulate motor and emotional behavior (Araki et al. 2001, West et al. 2002, Del Bel et al. 2005, Volke et al. 2003, Miguel and Nunes-de-Souza 2008). However, molecular mechanisms of these actions are not well understood. Since experimental seizures in vivo are often detected by the appearance of clonic movements (Del-Bel et al. 1997) the alterations of motor and emotional behavior by nNOS inhibition could influence the interpretation of results of such epileptological studies.

In the present study we attempted to elucidate effects of selective nNOS inhibition on some physiological and behavioral parameters. Under nNOS inhibition by 7-NI we carried out recordings of blood gasses, blood pressure and spontaneous EEG in adult conscious rats. To assess locomotion and exploratory behavior open field test (OF) was performed. Possible motor and limb coordination deficit were evaluated in a ladder rung walking test (Brima et al. 2013).

\section{Methods}

Animals

Eighty five adult male Wistar rats (280-350 g) from the local breeding of the Institute of Physiology (ASCR) were used to monitor arterial blood pressure $(n=10)$; to monitor blood gas levels $(n=16)$, to measure spontaneous brain activity and brain excitability $(n=43)$ and to assess changes in behavior $(\mathrm{n}=16)$. Rats were housed in standard plastic cages in temperaturecontrolled environment $\left(22 \pm 1{ }^{\circ} \mathrm{C}\right)$, humidity $50-60 \%$ with a 12-h light/dark cycle (lights on at 6 am) with free access to food and water. All experiments were performed in agreement with the Animal Protection Law of the Czech Republic (in compliance with EU 2010/63/EC), and the project was approved by the Animal Care and Use Committee of the Institute of Physiology of the Academy of Sciences of the Czech Republic. All efforts were made to minimize animal suffering and to reduce the number of animals used.

\section{Drug treatment}

7-NI was obtained from Sigma-Aldrich (Czech Republic) and dissolved in dimethyl sulfoxide (DMSO). The rats were injected intraperitoneally with either 7-NI $(25 \mathrm{mg} / \mathrm{kg}$ ) or vehicle (DMSO) in a total volume of $1 \mathrm{ml} / \mathrm{kg}$ body weight. The dose of 7-NI was selected on the basis of previous studies (Brožíčková and Otáhal 2013). Solutions were freshly prepared at the beginning of each experiment. Measurement times (10 min before, 30, 180 and $240 \mathrm{~min}$ after 7-NI treatment) were chosen according to our experiences with the drug. Maximal vascular effect was achieved $20 \mathrm{~min}$ after i.p. administration of the 7-NI. 
Continuous recording of blood pressure in conscious animals and blood gas analysis

To monitor arterial blood pressure (BP) and to obtain blood samples for blood gas analysis (BGA) a catheter was implanted into the common carotid artery. Anesthesia was induced with $5 \%$ isoflurane and anesthesia was further maintained with 1.5-2.5\% isoflurane during the surgical procedure. From ventral midline neck incision a trigonum caroticum was carefully exposed to avoid any damage to glomus caroticum and its innervations. After arteriotomy a plastic catheter (PE50) was inserted into the central portion of common carotid artery and fixed with ligations. The catheter was then passed under the skin and pulled out from a small nuchal incision. After postsurgical recovery (one day for blood gas analysis and $4 \mathrm{~h}$ for blood pressure recordings) animals were placed into a transparent plastic box and the catheter was washed with heparinized saline and connected to the pressure sensor (BLPR2, WPI, Germany) (Zicha et al. 2008). Blood pressure was recorded during three 5-min sessions. The first recording session took place before drug administration, the second and third session $30 \mathrm{~min}$ and $180 \mathrm{~min}$ respectively after drug administration and mean arterial pressure was calculated in Spike2 (CED, UK). To asses arterial blood gasses samples of arterial blood $(150 \mu \mathrm{l})$ were collected into a glass capillary (10 min before, 30, 180 and $240 \mathrm{~min}$ after drug application) and immediately analyzed by ABL5 Blood gas system (Radiometer, Denmark).

\section{Measurements of spontaneous EEG and brain excitability}

To monitor spontaneous and evoked cortical EEG, four recording and two stimulation epidural electrodes were implanted. Stimulation electrodes were placed over the sensorimotor cortical area of the right hemisphere at coordinates $\mathrm{AP}+1$ and -1 ; L $2 \mathrm{~mm}$, recording electrodes over the left hemisphere sensorimotor area (AP -1; L $2.5 \mathrm{~mm}$ ), parietal association area (AP 3; L $3 \mathrm{~mm}$ ), occipital visual area (AP 6; L $4 \mathrm{~mm}$ ) - and a parietal electrode also over the right hemisphere. Reference and grounding electrodes were inserted into the occipital bone over the cerebellum. The electrodes were connected to a microconnector and the whole assembly was fixed to the skull by means of two screws and dental acrylic. After surgery animals were allowed to recover for next 5 days.

Three sessions of EEG recordings were performed to assess the effect of 7-NI on spontaneous brain activity and on brain excitability. Rats were placed in a transparent box $(18 \times 28 \times 35 \mathrm{~cm})$ and connected to a custom-made cable for EEG recordings. EEG data were acquired at $2 \mathrm{kHz}$ and filtered at 2-500 $\mathrm{Hz}$ (RA16PA preamplifier and Pentusa Base Station; Tucker-Davis Technologies, USA) (Tolner et al. 2011). Experiments were performed at room temperature in freely moving rats. First recording session were measured before drug application, second and third 30 or 180 min after drug application respectively. Each session consisted of spontaneous EEG recording (5 min) and of a stimulation protocol to obtain an input-output (I-O) curve. Evoked responses were evoked with $0.5 \mathrm{~ms}$ biphasic pulses ranging from 0.4-5 $\mathrm{mA}$ using a constant-current stimulator (AM Systems, Australia).

Power spectra and Shanon entropy was calculated offline from $30 \mathrm{~s}$ epochs of the EEG signal using custom written scripts for MATLAB software (Mathworks, Inc., USA). For analysis of single evoked responses, the amplitude from the first negative wave (N1) to the following positive wave (P2) was measured.

\section{Behavioral measurement}

On the experimental day the rats were brought to the experimental room, marked, weighted and let to acclimatize for one hour.

\section{Open field test (OF)}

The test was performed $30 \mathrm{~min}$ (session 1) and $240 \mathrm{~min}$ (session 2) after the drug/vehicle administration. The duration of OF test was $5 \mathrm{~min}$. Each rat was placed in the left corner of the arena $(45 \times 45 \times 30 \mathrm{~cm})$. The behavior was videotaped and subsequently evaluated offline using computerized behavioral analysis systems EthoVision and Observer (Noldus Information Technology). The arena was carefully cleaned and wiped after each animal. The following behavioral variables were subsequently evaluated: locomotion (i.e. distance travelled), thigmotaxic scanning (i.e. time spent in locomotion along the walls of the OF), center time (i.e. time spent in the central section of the OF, $29 \times 29 \mathrm{~cm}$, see Fig. 3), rearing (upright posture both against and away from the wall), self-grooming (including scratching, fur licking and face washing).

\section{Ladder rung walking test}

The horizontal ladder rung walking test was performed $90 \mathrm{~min}$ after the drug/vehicle administration. The apparatus consisted of transparent side walls and removable metal rungs $(3 \mathrm{~mm}$ diameter, separation of 
$1 \mathrm{~cm}$ ), creating a floor allowing easy change of pattern (regular/irregular gaps). The ladder was elevated $30 \mathrm{~cm}$ above the ground with a empty starting cage and a refuge (home cage with the littermates) at the end. The width of the alley was adjusted to the size of the animal, to prevent the animal from turning around. The time to cross the entire length of the ladder was assessed in a session with regular gaps and then in a second session with irregular gaps. For the regular arrangements, the rungs were spaced at $2 \mathrm{~cm}$ intervals. For the irregular pattern, the distance of the rungs varied systematically from 1 to 5 $\mathrm{cm}$. If the rat failed to cross the ladder, the time was set to $60 \mathrm{~s}$. In addition, the mean number of errors in foot placement was calculated; an error representing any kind of foot slip was evaluated from video recordings.
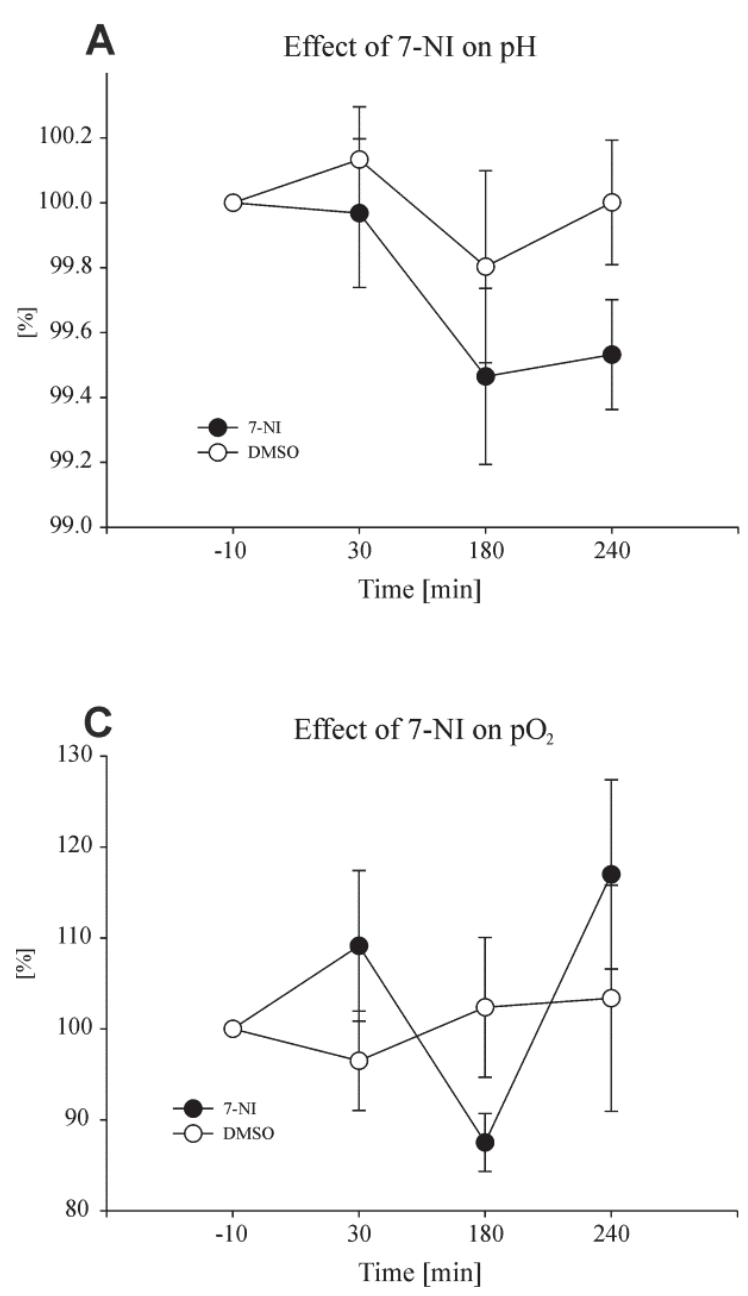

\section{Statistical analysis}

Data from physiological recordings were statistically evaluated using ANOVA for repeated measures and t-test when appropriate. The OF data were analyzed by a two-way repeated measure ANOVA with one between-group factor (DMSO, 7-NI) and one within subject factor (session 1, session 2). Degrees of freedom (df) were always $(1,13)$. The data from the ladder rung walking test were analyzed with one-way ANOVA. As for error of foot placement, the data were expressed as the percentage of errors from the total number of steps. When appropriate, subsequent comparisons were performed with a Student-Newman-Keuls test. The level of significance was set at $\mathrm{P}<0.05$. For statistical analysis the Sigma Stat3.5®SPSS package was used. All data are expressed as mean \pm standard error of the mean (S.E.M.).
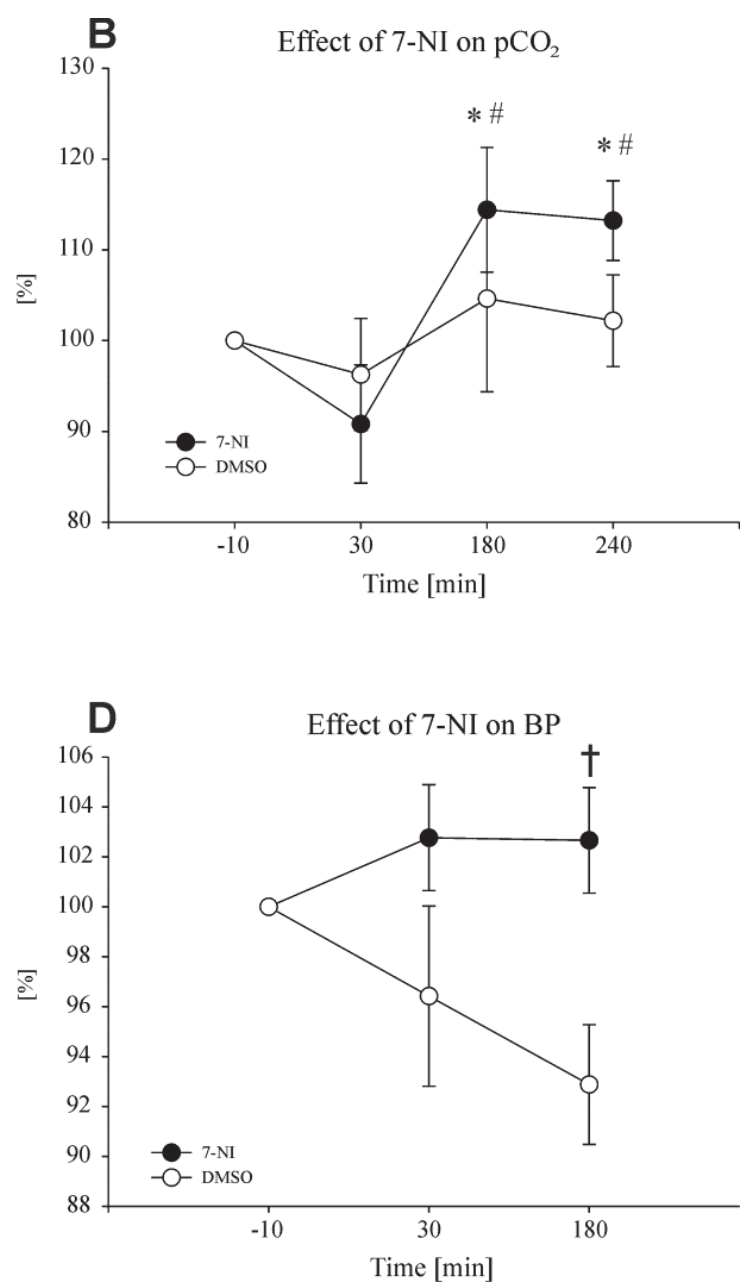

Fig. 1. Blood gas analysis before and after 7-NI and DMSO application (A-C). (A) Changes in blood pH in 7-NI and DMSO treated animals. (B) These changes were accompanied by a significant increase of $\mathrm{pCO}_{2} 180 \mathrm{~min}$ and 240 min after the application of 7-NI compared to the measuring at rest. (C) 7-NI had no significant effect on $\mathrm{pO}_{2}$ and $\mathrm{sO}_{2}$. (D) Procentual changes in blood pressure (BP) after 7-NI and DMSO treatment. At $180 \mathrm{~min}$ after the drug application a statistically significant difference in the BP value was observed between the 7-NI treated animals and DMSO treated animals. (* when compared to baseline values, \# when compared to values measured $30 \mathrm{~min}$ after drug treatment, + when compared to control animals $=\mathrm{P}<0.05$ ) 

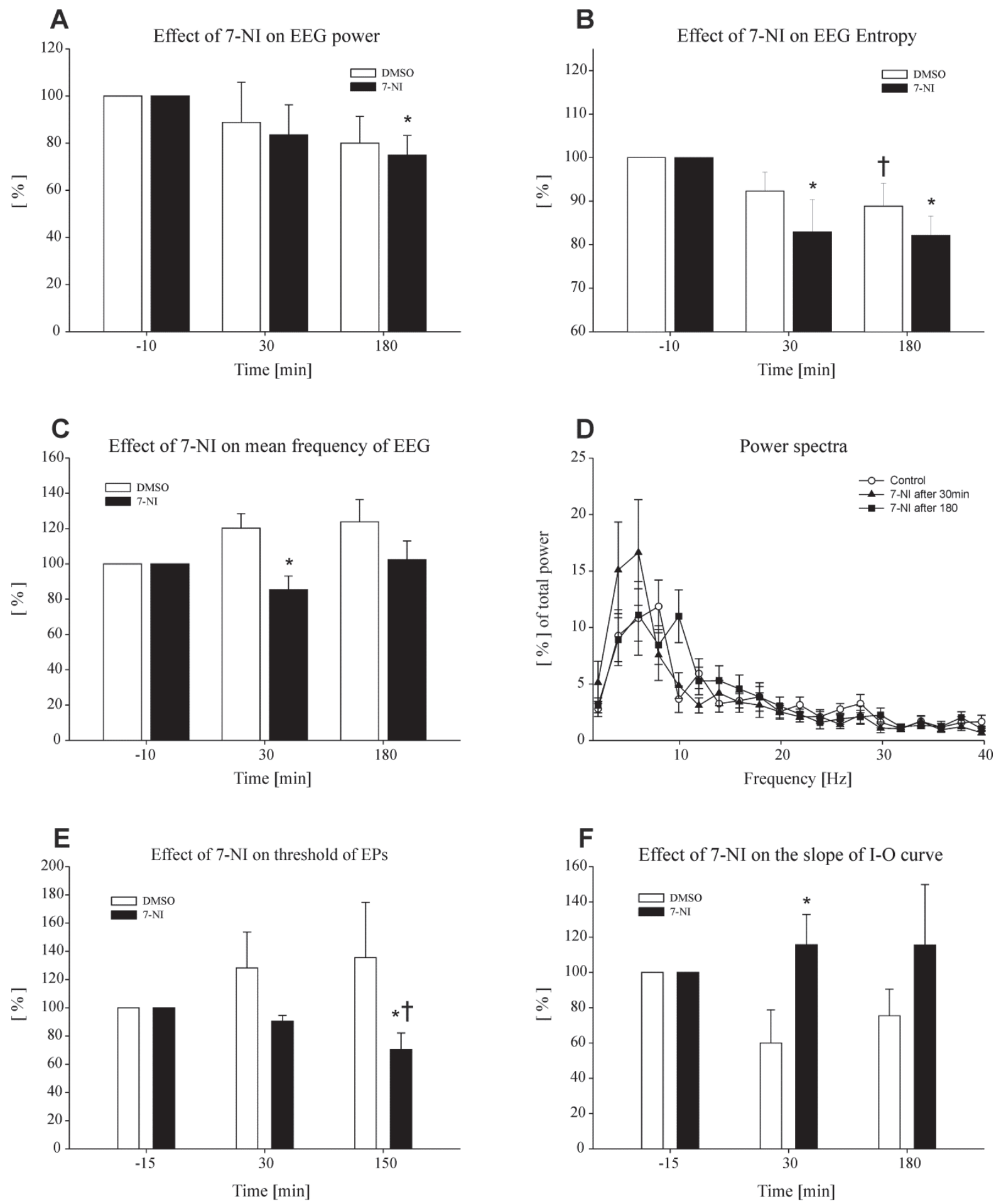

Fig. 2. (A-D) The effect of 7-NI on the power, entropy and frequency of the EEG. 7-NI induced significant changes in spontaneous EEG and evoked EEG responses. (A) The power of the spontaneous EEG decreased after 7-NI injection with time. (B) A significant decrease in EEG entropy occurred 30 and 180 min in 7-NI treated animals in comparison with basal values and also when compared to the DMSO group at $180 \mathrm{~min}$. (C, D) 7-NI induced a significant decrease shift of the mean frequency of the EEG to the left 30min after the treatment. (E-F) Procentual changes in EPs thresholds and in the slope of the input-output curves (I-O curve). (E) Procentual changes in EPs thresholds in comparison with their magnitudes before 7-NI or DMSO treatment. The thresholds of the EPs underwent a significant drop in 7-NI treated animals. DMSO induced an increase over the cross of the experiment. This increase was not significant. (F) Procentual changes in the slope of the input-output curves (I-O curve) in comparison with their magnitudes before 7-NI or DMSO treatment. 7-NI induced an increase in slope of the I-O curve in comparison with the curve obtained from measuring before 7-NI treatment. DMSO induced a non significant decrease in the slope of the I-O curve. However, 30 min after the drug application a statistically significant difference in the value of procentual BP changes was observed between the 7-NI and DMSO treated animals. (* when compared to baseline values, \# when compared to values measured $30 \mathrm{~min}$ after drug treatment, $\dagger$ when compared to control animals $=\mathrm{P}<0.05)$ 


\section{Results}

Effect of 7-NI on blood pressure in freely moving animals and blood gases

Systemic blood pressure measured $10 \mathrm{~min}$ before application of 7-NI or vehicle was $139.7 \pm 3.9$ $\mathrm{mm} \mathrm{Hg}$. Following the injection of 7-NI a non-significant rise in BP occurred at both time points. To be precise, $30 \mathrm{~min}$ after the drug treatment the increase was $102.77 \pm 2.12 \%$ and at $180 \mathrm{~min}$ after the drug administration it reached $102.66 \pm 2.11 \%$ when compared to baseline values (Fig. 1D). However, a statistically significant difference $(\mathrm{P}=0.016)$ between 7-NI and DMSO treated animals was detected $180 \mathrm{~min}$ after the treatment only.

The blood gas analysis revealed significant increase in $\mathrm{pCO}_{2}$ at $180 \mathrm{~min}(114.42 \pm 6.87 \%)$ and at $240 \mathrm{~min}(113.23 \pm 4.38 \%)$ after the application of $7-\mathrm{NI}$ when compared to values obtained $10 \mathrm{~min}$ before and $30 \mathrm{~min}$ after the 7-NI injection (Fig. 1B). 7-NI had no significant effect on $\mathrm{pH}$ or $\mathrm{pO}_{2}$ at all-time intervals (Fig. 1A,C). No significant alterations in blood gases were found after vehicle treatment (Fig. 1B,C).

\section{Effect of 7-NI on spontaneous EEG and brain excitability}

7-NI induced significant changes in spontaneous EEG and evoked EEG responses. The power of the spontaneous EEG decreased in both 7-NI and DMSO group with time and the power was significantly smaller in 7-NI group $180 \mathrm{~min}$ when compared to the baseline values (Fig. 2A). Accordingly, a significant decrease in
EEG entropy occurred 30 and $180 \mathrm{~min}$ in comparison with basal values and when compared to the DMSO group $180 \mathrm{~min}$ later (Fig. 2B). Compared to the baseline values 7-NI at dose of $25 \mathrm{mg} / \mathrm{kg}$ induced a significant decrease shift of the mean frequency of the EEG to the left (toward slow oscillations) $30 \mathrm{~min}$ after the treatment (Fig. 2C and D).

The evoked potentials (EPs) were composed of a small positive peak which was followed by a negative peak and by a second positive peak. Figures $2 \mathrm{~A}$ and $2 \mathrm{~B}$ show percentage changes in EPs thresholds and in the slope of the input-output curves (I-O curve) in comparison with their magnitudes before 7-NI or vehicle administration. Vehicle did not induce any significant changes in threshold magnitude during the entire experiment. The thresholds of the EPs underwent a significant drop in 7-NI treated animals. Changes are shown in Figure 2E. $180 \mathrm{~min}$ after 7-NI application, the threshold decreased to $(70.37 \pm 11.71 \%)$ compared to basal values and decreased to $(90.46 \pm 4.04 \%)$ compared to values obtained 30 min after 7-NI administration.

In vehicle treated animals, there was no significant decrease in the slope of the I-O curve. In 7-NI treated animals, a trend towards a slight increase in the IO curve slope was observed $30 \mathrm{~min}$ and $180 \mathrm{~min}$ after 7NI administration compared to baseline values. A statistically significant difference between the 7-NI and DMSO treated animals $(\mathrm{P}=0.049)$ as for the changes in the I-O curve slope was observed $30 \mathrm{~min}$ after the drug administration (Fig. 2F).
A

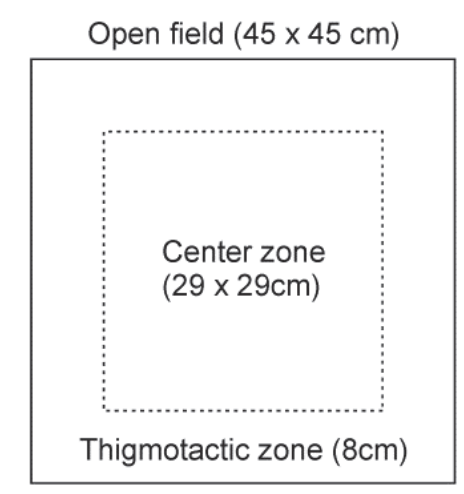

B

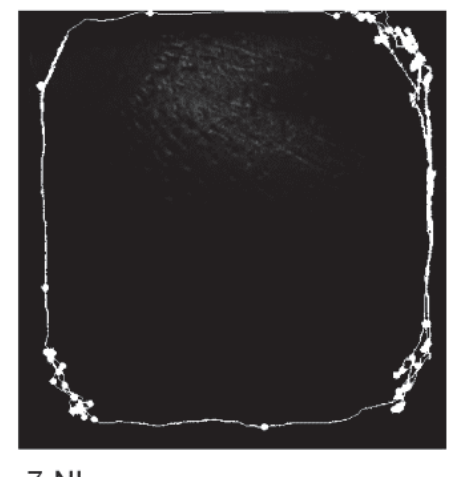

C

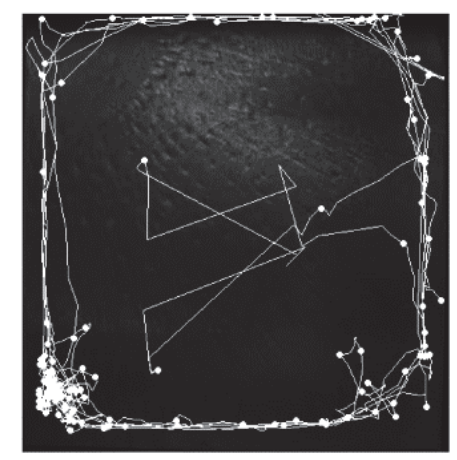

DMSO

Fig. 3. (A) Open field arena. Open field track in a typical 7-NI (B) treated subject and in a typical control subject (C).

\section{Effect of 7-NI in the OF test}

A schematic representation of the OF test and track moved are depicted in Figure 3. The analysis of the distance moved in the OF did not show an overall significant effect of treatment $(F=3.92, P=0.07)$ but a significant effect of session $(F=11.55, P=0.005)$ and 
interaction (treatment $\mathrm{x}$ session) effect ( $F=20.71$, $P<0.001)$. Post-hoc comparison revealed that the $7-\mathrm{NI}$ decreased significantly the distance moved in Session 1 compared to vehicle (DMSO) treated animals. No change was observed in 7-NI treated rats in the Session 2 compared to Session 1. On the other hand, in DMSO treated rats a significant decrease in distance moved was found in Session 2 compared to Session 1 (Fig. 4A). The analysis of the time spent in the arena centre revealed a marginal significant differences of treatment $(F=4.60$, $P=0.05)$, but not of session $(F=0.71, P=0.41)$ and interaction $(F=0.21, P=0.65)$. As for rearing number, ANOVA did not showed statistical differences of treatment $(F=3.50, P=0.08)$, session $(F=1.88, P=0.19)$ and interaction effect $(F=2.98, \quad P=0.11)$; although according to t-test the decrease of the rearing number in Session 1 in animals treated with 7-NI was significant when compared to DMSO treated animals (Fig. 4C). Finally, as for grooming there was a significant effect of treatment $(F=13.77, P=0.003)$ but neither significant effect of session $(\mathrm{F}=3.19, \mathrm{P}=0.09)$ or interaction $(F=1.02$, $P=0.33)$. The animals treated with 7-NI spent less time in grooming in both sessions compared to DMSO treated ones (Fig. 4D).

\section{Effect of 7-NI on the ladder rung walking test}

The overall analysis did not revealed difference in the time spent crossing the entire length of the ladder either in the session performed with regular patterns or irregular patterns $F(3,28)=2.88, P=0.053$ (Fig. 4E). As for errors in foot placement, there was a significant difference between 7-NI and DMSO treated groups $(F(3,28)=4.020, P=0.017$, Fig. 3F). The post-hoc test showed that animals treated with $7 \mathrm{NI}$ reached a higher percent of foot slipped off in both sessions.

\section{Discussion}

The goal of the experiment was to identify the potential physiological and behavioral alterations induced by the inhibition of nNOS by 7-NI in conscious adult rats. Specifically we were interested in elucidating the role of nNOS inhibition on systemic blood pressure, arterial blood gases levels, spontaneous and evoked neuronal activity as well as on behavioral parameters such as locomotion, exploratory behavior and skilled walking. Our study confirmed that 7-NI indeed widely influences the parameters under investigation.
Firstly, we confirmed that 7-NI influences systemic blood pressure. 7-NI induced an increase in systemic blood pressure in comparison with vehicle (DMSO) treated animals. This increase was significant $180 \mathrm{~min}$ after 7-NI administration. However, when compared to baseline values, the slight rise observed in blood pressure was not significant. A similar small increase was also reported in other studies (Kurihara et al. 1998). Inhibition of nNOS by 7-NI or other, more selective nNOS inhibitors was reported to increase (Zagvazdin et al. 1996), decrease (Kakoki et al. 2001) or not to change blood pressure (Yoshida et al. 1994, Zagvazdin et al. 1996). Because 7-NI is recognized to rather specifically inhibit neuronal nitric oxide synthase (Moore et al. 1993) the slight 7-NI increase in systemic blood pressure could probably have been due to the elimination of the neurally mediated vascular action of nitric oxide derived from nNOS. In the past years, there has been a dispute about 7-NI specificity for nNOS. Results from different investigators indicate that 7-NI does not inhibit endothelial NO synthase (Bryan and Grisham 2007, Faraci and Breese 1993, Moore et al. 1993). However, there is evidence that 7-NI may inhibit eNOS in vivo (Zagvazdin et al. 1996a). Thus the rise in blood pressure could also be due to partial inhibition of eNOS. Moreover, nNOS is thought to play an important role in regulating BP via sympathetic nerve activity (SNA). It was reported that nNOS inhibition in vivo causes sympathetic activation and thus increases BP (Young et al. 2009).

The blood gas analysis revealed that 7-NI influences arterial blood gas levels. 7-NI produced a statistically significant raise in $\mathrm{pCO}_{2}$ three hours after the drug application. This raise was significant not only in comparison with the vehicle treated animals, but also when compared to baseline values and values obtained $30 \mathrm{~min}$ after 7-NI administration. This increase was accompanied by no significant change in blood $\mathrm{pH}$. Concomitantly with the rise in $\mathrm{pCO}_{2}$ we observed a decrease in $\mathrm{pO}_{2}$, which could indicate that these changes may be of respiratory origin. Indeed, a reduction in ventilation was reported in other studies after 7-NI injection (Nakano et al. 2001). The mechanism of action of NO on respiratory control is likely by enhancing the excitability of the neurons involved in the generation of central respiratory activity (Nakano et al. 2001) and/or by affecting thermoregulation (Perotti et al. 1999). 

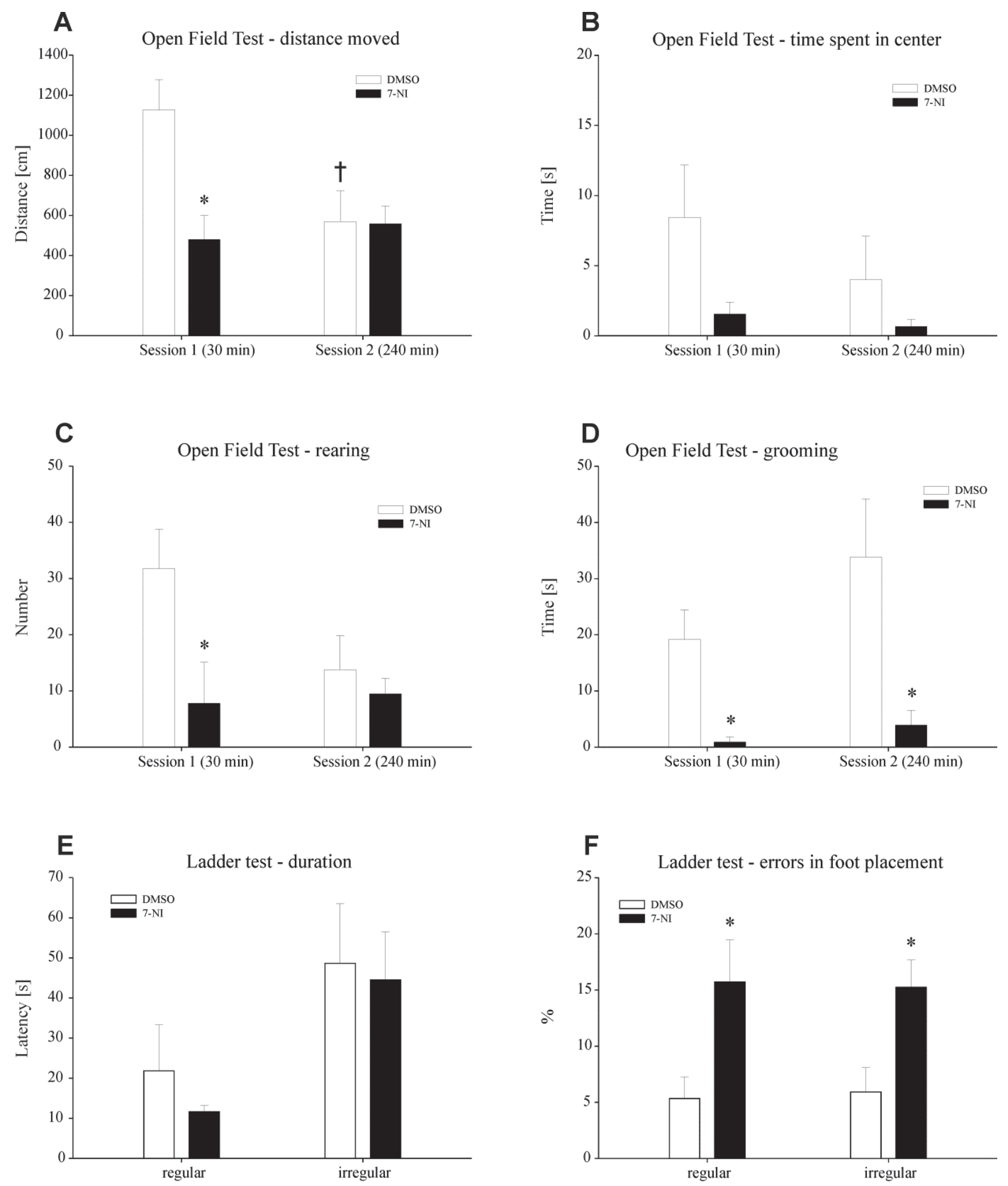

Fig. 4. Results from the openfield test (A-D) and Ladder test (E-F) in control and 7-NI treated animals. (A) 7-NI decreased significantly the distance moved in Session 1 compared to vehicle (DMSO) treated animals. No change was observed in 7-NI treated rats in the Session 2 compared to Session 1. (B) The analysis of the time spent in the arena centre revealed a marginal significant differences of treatment $(F=4.60, P=0.05)$, but not of session $(F=0.71, P=0.41)$ and interaction $(F=0.21, P=0.65)$. (C) A decrease of the rearing number in Session 1 in animals treated with 7-NI was significant when compared to DMSO treated animals. (D) The animals treated with 7-NI spent less time in grooming in both sessions compared to DMSO treated ones. (E) The overall analysis did not reveal a difference in the time spent crossing the entire length of the ladder either in the session performed with regular patterns or irregular patterns. (F) Animals treated with 7NI reached a higher percent of missteps in both sessions. (* when compared to baseline values, \# when compared to values measured 30 min after drug treatment, + when compared to control animals $=\mathrm{P}<0.05$ ) 
Traditional behavioral tests, such as the OF test measure an animal's responsiveness to a novel environment. The behavior in the OF is complex and may include components of arousal, novelty seeking, fear response and stereotypy (Kas et al. 2008). Administration of 7-NI at the dose of $25 \mathrm{mg} / \mathrm{kg}$ i.p. suppressed locomotion, exploratory rearing and grooming behavior 30 min after drug administration. In the test performed at $240 \mathrm{~min}$ the drug failed to reveal a similar effect, suggesting that 7-NI suppressed transiently the OF behavior. Our data are in agreement with a previous study showing that $7-\mathrm{NI}(10 \mathrm{mg} / \mathrm{kg})$ induced decrease in locomotion in adult rats when tested $40 \mathrm{~min}$ after the administration (Volke et al. 1997). Similarilly, in mice 7-NI at the dose of $120 \mathrm{mg} / \mathrm{kg}$ reduced motor activity $1 \mathrm{~h}$ following administration, but faded away $3 \mathrm{~h}$ later (Dzoljic et al. 1997a). Finally, 7-NI suppressed time spent in the center part of the arena as well as rearing and grooming behavior at both intervals indicating an increase in anxiety/fear emotionality. It is conceivable that the suppression of behavioral profile actually indicate a rather an anxiogenic-like effect. In this respect our results are in contradiction with studies indicating that 7-NI possesses an anxiolytic-like effect in both rats and mice (Dunn et al. 1998, Volke et al. 2003, Yildiz et al. 2000). Decrease in all behavioral parameters, except grooming was observed in control animals, but not in 7-NI treated animals, which might indicate inability of the 7-NI treated animals to adapt to novel environment with repeated exposure to OF.

With respect to the ladder rung walking test, the 7-NI treated rats made more errors in foot placement than the control animals. These findings indicate that the inhibition of nNOS by 7-NI affects the stepping and balance behavior on the ladder. Similarly, adult nNOS knockout mice (nNOS -/-) were observed to present balance and motor coordination alternations (Kriegsfeld et al. 1999a, b, Weitzdoerfer et al. 2004). Furthermore, 7-NI induced motor deficit at the doses of $40-160 \mathrm{mg} / \mathrm{kg}$ in mice in motor tests (Araki et al. 2001). In our experiment the errors that occurred in foot placement did not interrupt the walking as all the animals crossed the ladder within 90 s. Surprisingly, although the locomotion in the OF test was decreased all animals treated with 7-NI successfully passed the ladder even if many missteps occurred. Reaching home cage with littermates is likely a strong motivation to overcome the obstacle. In this respect the results are in agreement with the study of Volke et al. (2003) and Dzoljic et al. (1997a) showing that 7-NI decreased locomotion and produce motor incoordination.

Many factors might account for this effect of 7-NI on motor behavior. Several in vivo studies have demonstrated that NO may modulate several neurotransmitter systems in the central nervous system (Wegener et al. 2000). Following both local and systemic administration of 7-NI an increase in dopamine and serotonin levels in the ventral hippocampus of freely moving rats was observed (Wegener et al. 2000). It is assumed that serotonin plays a role in the regulation of mood, cognition, motor behavior and a disruption of serotoninergic transmission is implicated in several pathophysiological states, including affective disorders (Chanrion et al. 2007). Additionally, a condition characterized by muscular rigidity and fixity of posture regardless of external stimuli, as well as decreased sensitivity to pain, termed catalepsy, was also observed in both NO-sGC and NOS inhibitors in adult mice that lasted for at least $2 \mathrm{~h}$ (Echeverry et al. 2007).

In concert with the 7-NI induced alterations of systemic parameters and motor behavior, the spontaneous EEG power was suppressed. Following the i.p. administration of 7-NI the EEG power was suppressed relative to the pre-treatment values throughout the whole experiment. A similar 7-NI induced reduction of the power of the EEG signal was observed in other electrophysiological studies performed in other brain regions (Dzoljic et al. 1997b, Ferraro et al. 2004). Dzoljic proved that in conscious rats, the power of EEG recorded from parietal cortices was suppressed in each frequency range by 7 -NI. However, this effect was more prominent in the high theta frequency band (7-9 Hz). High frequency of theta rhythm in rats is associated with locomotion and voluntary movements (Dzoljic et al. 1997b). This decrease of high theta rhythm is consistent with the reduced locomotion, observed in this study. The same study of Dzoljic showed that the administration of 7-NI was characterized by arousal-like EEG/EMG pattern (low EEG amplitudes and high EMG amplitudes) and reduced behavioral activity (decreased locomotion and occasional loss of righting reflex and ptosis) (Dzoljic et al. 1997b). The precise way of the observed central modulatory action of 7-NI is still not known.

We have observed that the thresholds of the EPs underwent a significant drop in 7-NI treated animals and that 7-NI induced an increase in slope of the I-O curve in comparison with the curve obtained from measuring before 7-NI treatment. Therefore, we can assume that 
7-NI increased cortical excitability. Up to now, the role of endogenous NO in modulation of the brain excitability in vivo remains unclear. Additionally, number of studies show an anticonvulsant action obtained with NOS inhibitors (Del-Bel et al. 1997), other reports suggests that inhibitors of nitric oxide synthase (NOS) are proconvulsant (Dzoljic et al. 1997a,b, Moncada et al. 1992, Montecot et al. 1998). The effects of NOS inhibitors vary with the model of seizure, the dose of convulsant used, the selectivity of the inhibitor, and the strain of rats used in experiments. Our results indicate that this increase of brain excitability and controversial results in epileptologic studies may be caused by the systemic effects of 7-NI namely alteration of blood gasses.

\section{Conclusions}

Our results show that in conscious rats 7-NI induces a rise in arterial blood pressure and significantly influences levels of $\mathrm{pCO}_{2}$ in arterial blood indicating its systemic effect. Results from behavioral tests show that 7-NI at the dose of $25 \mathrm{mg} / \mathrm{kg}$ affects locomotion and exploratory activity and induces walking incoordination. Electrophysiological recordings demonstrate a suppression of the spontaneous EEG power, however, the thresholds of the EPs underwent a significant drop in 7-NI treated animals and the slope of the I-O curve increased in comparison with the curve obtained from measuring before 7-NI treatment. Therefore, we can assume that 7-NI increased cortical excitability.

\section{Conflict of Interest}

There is no conflict of interest.

\section{Acknowledgements}

This study was supported by Grants number P303/10/0999, P304/11/P386 and P304/12/G069 from Czech Science Foundation and project AV0Z50110509.

\section{References}

ARAKI T, MIZUTANI H, MATSUBARA M, IMAI Y, MIZUGAKI M, ITOYAMA Y: Nitric oxide synthase inhibitors cause motor deficits in mice. Eur Neuropsychopharmacol 11: 125-133, 2001.

BAL-PRICE A, BROWN GC: Inflammatory neurodegeneration mediated by nitric oxide from activated glia-inhibiting neuronal respiration, causing glutamate release and excitotoxicity. J Neurosci 21: 6480-6491, 2001.

BEAMER E, OTAHAL J, SILLS GJ, THIPPESWAMY T: N(w)-propyl-L-arginine (L-NPA) reduces status epilepticus and early epileptogenic events in a mouse model of epilepsy: behavioural, EEG and immunohistochemical analyses. Eur J Neurosci 36: 3194-3203, 2012.

BON CL, GARTHWAITE J: On the role of nitric oxide in hippocampal long-term potentiation. J Neurosci 23: 1941 1948, 2003.

BRIMA T, MIKULECKA A, OTAHAL J: Impacts of perinatal induced photothrombotic stroke on sensorimotor performance in adult rats. Physiol Res 62: 85-94, 2013.

BROWN GC: Regulation of mitochondrial respiration by nitric oxide inhibition of cytochrome c oxidase. Biochim Biophys Acta 1504: 46-57, 2001.

BROŽÍČKOVÁ C, OTÁHAL J: Effect of an inhibitor of neuronal nitric oxide synthase 7-nitroindazole on cerebral hemodynamic response and brain excitability in urethane-anesthetized rats. Physiol Res 62 (Suppl 1): S57-S66, 2013.

BRYAN NS, GRISHAM MB: Methods to detect nitric oxide and its metabolites in biological samples. Free Radic Biol Med 43: 645-657, 2007.

CALABRESE V, MANCUSO C, CALVANI M, RIZZARELLI E, BUTTERFIELD DA, STELLA AM: Nitric oxide in the central nervous system: neuroprotection versus neurotoxicity. Nat Rev Neurosci 8: 766-775, 2007.

CALIXTO AV, DUARTE FS, DUZZIONI M, NASCIMENTO HACKL LP, FARIA MS, DE LIMA TC: Role of ventral hippocampal nitric oxide/cGMP pathway in anxiety-related behaviors in rats submitted to the elevated T-maze. Behav Brain Res 207: 112-117, 2010.

CHANRION B, MANNOURY LA COUR C, BERTASO F, LERNER-NATOLI M, FREISSMUTH M, MILLAN MJ, BOCKAERT J, MARIN P: Physical interaction between the serotonin transporter and neuronal nitric oxide synthase underlies reciprocal modulation of their activity. Proc Natl Acad Sci USA 104: 8119-8124, 2007. 
DEL-BEL EA, OLIVEIRA PR, OLIVEIRA JA, MISHRA PK, JOBE PC, GARCIA-CAIRASCO N: Anticonvulsant and proconvulsant roles of nitric oxide in experimental epilepsy models. Braz J Med Biol Res 30: 971-979, 1997.

DEL BEL EA, GUIMARAES FS, BERMUDEZ-ECHEVERRY M, GOMES MZ, SCHIAVETO-DE-SOUZA A, PADOVAN-NETO FE, TUMAS V, BARION-CAVALCANTI AP, LAZZARINI M, NUCCI-DA-SILVA LP, DE PAULA-SOUZA D: Role of nitric oxide on motor behavior. Cell Mol Neurobiol 25: 371-392, 2005.

DUNN RW, REED TA, COPELAND PD, FRYE CA: The nitric oxide synthase inhibitor 7-nitroindazole displays enhanced anxiolytic efficacy without tolerance in rats following subchronic administration. Neuropharmacology 37: 899-904, 1998.

DZOLJIC E, DE VRIES R, DZOLJIC MR: New and potent inhibitors of nitric oxide synthase reduce motor activity in mice. Behav Brain Res 87: 209-212, 1997a.

DZOLJIC E, VAN LEEUWEN R, DE VRIES R, DZOLJIC MR: Vigilance and EEG power in rats: effects of potent inhibitors of the neuronal nitric oxide synthase. Naunyn Schmiedebergs Arch Pharmacol 356: 56-61, $1997 \mathrm{~b}$.

ECHEVERRY MB, SALGADO ML, FERREIRA FR, DA-SILVA CA, DEL BEL EA: Intracerebroventricular administration of nitric oxide-sensitive guanylyl cyclase inhibitors induces catalepsy in mice. Psychopharmacology (Berl) 194: 271-278, 2007.

ENGELHARDT T, LOWE PR, GALLEY HF, WEBSTER NR: Inhibition of neuronal nitric oxide synthase reduces isoflurane MAC and motor activity even in nNOS knockout mice. Br J Anaesth 96: 361-366, 2006.

ESPLUGUES JV: NO as a signalling molecule in the nervous system. Br J Pharmacol 135: 1079-1095, 2002.

FARACI FM, BREESE KR: Nitric oxide mediates vasodilatation in response to activation of N-methyl-D-aspartate receptors in brain. Circ Res 72: 476-480, 1993.

FERRARO G, SARDO P, DI GIOVANNI G, FILECCIA R, LA GRUTTA V: CCK-8S systemic administration blocks the 7-nitroindazole-induced effects on the EEG of striatum and globus pallidus: a FFT analysis in the rat. In Vivo 18: 317-323, 2004.

FORSTERMANN U, SESSA WC: Nitric oxide synthases: regulation and function. Eur Heart J 33: 829-837d, 2012.

FORSTERMANN U, POLLOCK JS, TRACEY WR, NAKANE M: Isoforms of nitric-oxide synthase: purification and regulation. Methods Enzymol 233: 258-264, 1994.

GARTHWAITE J, CHARLES SL, CHESS-WILLIAMS R: Endothelium-derived relaxing factor release on activation of NMDA receptors suggests role as intercellular messenger in the brain. Nature 336: 385-388, 1988.

HOFFMEYER HW, ENAGER P, THOMSEN KJ, LAURITZEN MJ: Nonlinear neurovascular coupling in rat sensory cortex by activation of transcallosal fibers. J Cereb Blood Flow Metab 27: 575-587, 2007.

ITOH K, WATANABE M: Paradoxical facilitation of pentylenetetrazole-induced convulsion susceptibility in mice lacking neuronal nitric oxide synthase. Neuroscience 159: 735-743, 2009.

KAKOKI M, ZOU AP, MATTSON DL: The influence of nitric oxide synthase 1 on blood flow and interstitial nitric oxide in the kidney. Am J Physiol 281: R91-R97, 2001.

KAS MJ, DE MOOIJ-VAN MALSEN AJ, OLIVIER B, SPRUIJT BM, VAN REE JM: Differential genetic regulation of motor activity and anxiety-related behaviors in mice using an automated home cage task. Behav Neurosci 122: 769-776, 2008.

KOVACS R, RABANUS A, OTAHAL J, PATZAK A, KARDOS J, ALBUS K, HEINEMANN U, KANN O: Endogenous nitric oxide is a key promoting factor for initiation of seizure-like events in hippocampal and entorhinal cortex slices. J Neurosci 29: 8565-8577, 2009.

KRIEGSFELD LJ, DEMAS GE, LEE SE Jr, DAWSON TM, DAWSON VL, NELSON RJ: Circadian locomotor analysis of male mice lacking the gene for neuronal nitric oxide synthase (nNOS-/-). J Biol Rhythms 14: 20-27, 1999a.

KRIEGSFELD LJ, ELIASSON MJ, DEMAS GE, BLACKSHAW S, DAWSON TM, NELSON RJ, SNYDER SH: Nocturnal motor coordination deficits in neuronal nitric oxide synthase knock-out mice. Neuroscience 89: 311 315, 1999b.

KURIHARA N, ALFIE ME, SIGMON DH, RHALEB NE, SHESELY EG, CARRETERO OA: Role of nNOS in blood pressure regulation in eNOS null mutant mice. Hypertension 32: 856-861, 1998.

MIGUEL TT, NUNES-DE-SOUZA RL: Anxiogenic-like effects induced by NMDA receptor activation are prevented by inhibition of neuronal nitric oxide synthase in the periaqueductal gray in mice. Brain Res 1240: 39-46, 2008 . 
MONCADA C, LEKIEFFRE D, ARVIN B, MELDRUM B: Effect of NO synthase inhibition on NMDA- and ischaemia-induced hippocampal lesions. Neuroreport 3: 530-532, 1992.

MONTECOT C, RONDI-REIG L, SPRINGHETTI V, SEYLAZ J, PINARD E: Inhibition of neuronal (type 1) nitric oxide synthase prevents hyperaemia and hippocampal lesions resulting from kainate-induced seizures. Neuroscience 84: 791-800, 1998.

MOORE PK, BABBEDGE RC, WALLACE P, GAFFEN ZA, HART SL: 7-Nitro indazole, an inhibitor of nitric oxide synthase, exhibits anti-nociceptive activity in the mouse without increasing blood pressure. $\mathrm{Br} J$ Pharmacol 108: 296-297, 1993.

NAKANO H, LEE SD, RAY AD, KRASNEY JA, FARKAS GA: Role of nitric oxide in thermoregulation and hypoxic ventilatory response in obese Zucker rats. Am J Respir Crit Care Med 164: 437-442, 2001.

PEROTTI CA, NOGUEIRA MS, ANTUNES-RODRIGUES J, CARNIO EC: Effects of a neuronal nitric oxide synthase inhibitor on lipopolysaccharide-induced fever. Braz J Med Biol Res 32: 1381-1387, 1999.

SCATENA R, BOTTONI P, BOTTA G, MARTORANA GE, GIARDINA B: The role of mitochondria in pharmacotoxicology: a reevaluation of an old, newly emerging topic. Am J Physiol 293: C12-C21, 2007.

SILVERMAN RB: Design of selective neuronal nitric oxide synthase inhibitors for the prevention and treatment of neurodegenerative diseases. Acc Chem Res 42: 439-451, 2009.

STEFANOVIC B, SCHWINDT W, HOEHN M, SILVA AC: Functional uncoupling of hemodynamic from neuronal response by inhibition of neuronal nitric oxide synthase. J Cereb Blood Flow Metab 27: 741-754, 2007.

TOLNER EA, HOCHMAN DW, HASSINEN P, OTAHAL J, GAILY E, HAGLUND MM, KUBOVA H, SCHUCHMANN S, VANHATALO S, KAILA K: Five percent $\mathrm{CO}_{2}$ is a potent, fast-acting inhalation anticonvulsant. Epilepsia 52: 104-114, 2011.

VOLKE V, KOKS S, VASAR E, BOURIN M, BRADWEJN J, MANNISTO PT: Inhibition of nitric oxide synthase causes anxiolytic-like behaviour in an elevated plus-maze. Neuroreport 6: 1413-1416, 1995.

VOLKE V, SOOSAAR A, KÕKS S, BOURIN M, MÄNNISTÖ PT, VASAR E: 7-Nitroindazole, a nitric oxide synthase inhibitor, has anxiolytic-like properties in exploratory models of anxiety. Psychopharmacology 131: 399-405, 1997.

VOLKE V, WEGENER G, BOURIN M, VASAR E: Antidepressant- and anxiolytic-like effects of selective neuronal NOS inhibitor 1-(2-trifluoromethylphenyl)-imidazole in mice. Behav Brain Res 140: 141-147, 2003.

WEGENER G, VOLKE V, ROSENBERG R: Endogenous nitric oxide decreases hippocampal levels of serotonin and dopamine in vivo. Br J Pharmacol 130: 575-580, 2000.

WEITZDOERFER R, HOEGER H, ENGIDAWORK E, ENGELMANN M, SINGEWALD N, LUBEC G, LUBEC B: Neuronal nitric oxide synthase knock-out mice show impaired cognitive performance. Nitric Oxide 10: 130140, 2004.

WEST AR, GALLOWAY MP, GRACE AA: Regulation of striatal dopamine neurotransmission by nitric oxide: effector pathways and signaling mechanisms. Synapse 44: 227-245, 2002.

YILDIZ F, ULAK G, ERDEN BF, GACAR N: Anxiolytic-like effects of 7-nitroindazole in the rat plus-maze test. Pharmacol Biochem Behav 65: 199-202, 2000.

YOSHIDA T, LIMMROTH V, IRIKURA K, MOSKOWITZ MA: The NOS inhibitor, 7-nitroindazole, decreases focal infarct volume but not the response to topical acetylcholine in pial vessels. J Cereb Blood Flow Metab 14: 924929, 1994.

YOUNG CN, FISHER JP, GALLAGHER KM, WHALEY-CONNELL A, CHAUDHARY K, VICTOR RG, THOMAS GD, FADEL PJ: Inhibition of nitric oxide synthase evokes central sympatho-excitation in healthy humans. J Physiol 587: 4977-4986, 2009.

ZAGVAZDIN Y, SANCESARIO G, WANG YX, SHARE L, FITZGERALD ME, REINER A: Evidence from its cardiovascular effects that 7-nitroindazole may inhibit endothelial nitric oxide synthase in vivo. Eur $J$ Pharmacol 303: 61-69, 1996.

ZICHA J, DOBESOVA Z, KUNES J: Late blood pressure reduction in SHR subjected to transient captopril treatment in youth: possible mechanisms. Physiol Res 57: 495-498, 2008. 